\title{
Teaching Accounting Online: Dealing With Challenging Situations
}

Muroki F. Mwaura, (E-mail: mwauram@wpunj.edu), William Paterson University Andrew B. Nyaboga, (E-mail: nyabogaa@wpunj.edu), William Paterson University

\begin{abstract}
This paper chronicles the issues and concerns of teaching an online accounting course. The issues discussed in this paper constitute the barest minimum that online instructors should address as they contemplate offering an online accounting course. Analysis of the following crucial factors that impact online teaching such as, knowledge of the online process; technical skills of online teaching; online communication and moderation skills; confidence and motivation are presented. This paper will present an analysis of teaching and learning issues, which may provide the basis of guidelines for best practice. It is further noted in this paper that effective institutional support is equally instrumental in successful implementation of online teaching.
\end{abstract}

\section{Introduction And Literature Review}

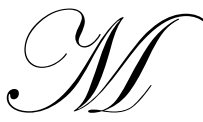

anagerial Accounting Online course was first offered in the fall semester 2000. During the summer 2000 , some instructors and I attended an online teaching session in preparation for the course. At the end of the training workshop, the instructors assumed that they were ready for the course. Lecture outlines and notes were prepared and the instructors were ready to start the course. But were they really ready? Did they have all the pieces together? Sadly, I have to admit that when the course started I was ill prepared and so were my colleagues.

A major deficiency in the training program was the failure of the trainers to alert the neophytes of the current concerns surrounding online teaching that were freely available in professional literature. We were given the impression that we are indeed professionals and all we needed was to get acquainted with Black Board platform and all will be well. The trainers in our workshop did not appear to be aware that some if not all courses needed course cartridges. This is a topic that should have been discussed during the training session but it was entirely ignored. The instructions on course cartridge software were emailed to the instructors by the publishers for them to download to their computers system a week or so before classes started. How was a neophyte supposed to know how to download a course cartridge on a university-wide computer system? This information was passed on to the Online Course Management team at the university for action. Passing on this task to the Online Course Management team essentially left the instructors out of the loop and the problems which arose in the course left the instructor is in a quandary accompanied with moments of anguish and frustration. Who do you contact when instructor or the students run into problems? The publishers, the Online Management team, or the Black Board Vendors?

While online teaching and learning is poised for explosive growth, there are still critical pedagogical issues that need to be revisited on a regular basis. Richard Flay (2001) suggests that pedagogical use of certain online features should be tailored to the needs of specific academic areas. For example, the use of online quizzes maybe a strong feature of an accounting or mathematics courses but maybe quite inappropriate for an English course. It goes without saying that the instructor is ultimately responsible for the execution of the course and the buck cannot be passed on to anyone else. A major concern of online teaching is the quality of instruction. This matter has been the 
subject of extensive research. Cathy Gunn (2001) offers the following framework for preparing an online course:

- $\quad$ knowledge of the online process;

- $\quad$ technical skills of online teaching;

- $\quad$ online communication and moderation skills;

- $\quad$ content expertise;

- $\quad$ confidence and motivation to teach online;

- $\quad$ Contextual influences on success of online learning.

In a 2000 article, Patrick Fahy, laments the contradictions inherent in Internet teaching. He expresses his concern in the following words, "the Internet illustrates how online teaching technologies have been a mixed blessing. The Internet's potential advantages as a teaching tool stem from the fact that it is engrossing and inherently interesting, incorporates multi-sensory uses of media, provides enormous numbers of connections to other sources of information and interaction, allows everyone an individualized experience, and can both reflect and be a creation of teachers and learners. However, these same characteristics also account for some of the Internet's major weaknesses as a teaching tool. Any plan to use the Internet and other new technologies as teaching tools must begin with a quality-oriented assessment of the given technology's fitness for use as a teaching tool."

Tim S. Roberts and David T. Jones (2000), describe four models of online teaching:

- $\quad$ The naive model, which is the most widely used, may be characterized as "putting lecture notes on the World Wide Web" with no opportunities for interaction or feedback.

- The standard model attempts to make active use of the Web's technology by allowing a significant degree of communication and interaction between students and staff, including through a subject home page, electronic copies of the printed materials dispatched to students before the semester, lecture slides in PowerPoint format, additional notes arising from on-campus lectures and tutorials, copies of past examinations, and links to the electronic mailing list for the subject.

- The evolutionary model attempts to address several key issues not addressed in the standard model by allowing the exact method of a course's delivery to evolve from semester to semester, based on identified strengths and weaknesses and weekly anonymous feedback from students.

- $\quad$ The radical model dispenses with lectures entirely. Instead, students are assigned to groups and learn by interacting among themselves and using existing Web-based resources, with academic staff members providing guidance as and when required.

The conduct of Managerial Accounting course closely follows the standard model, which in my view and experience is probably superior to any of the other models described in this paper. Copies of sample solutions to problems in the textbook, midterm examinations, final examinations, discussion questions, and lecture notes are posted on the Black Board course website at the beginning of the semester. As the semester progresses, lecture notes are updated to take into consideration perceived difficulties in comprehending chapter materials.

Below are some fundamental issues that this paper addresses. It is not a panacea but a soft approach to handle some of the critical issues when teaching online accounting course

\section{Instructor Training}

Online instructors should be thoroughly familiar with their institution's computing facilities that support online teaching.

Before you commit to a particular online course package from one of the publisher's, you must first ascertain that the operating system of your server is compatible with the course ware that you are going to use. Let me give an example. After attending a Prentice Hall seminar on technology use in classroom, I was greatly impressed by their online teaching tools and I committed to using one of their textbooks as the principle resource for my Managerial Accounting course in the following semester. In the months preceding the beginning of the semester, I had support from the publisher in terms of my development. 


\section{Blackboard Or WEBCT?}

There probably is an even split between the number of course offered through Blackboard and WEBCT platforms. Which one is preferable to the other? The answer to this question may be user specific. I personally have not had any familiarity with WEBCT and I cannot comment on its capability. I am familiar with Blackboard and I can confidently comment on its functionality.

\section{Publisher's Course Cartridges}

There always seems to be some issue regarding the compatibility of publisher's course cartridges with the operating system used to run blackboard. For reasons best known to publishers, course cartridges are always geared toward the latest versions of Blackboard or WEBCT. When problems arise with the use of the resources, it is extremely difficult for the instructor to know who to contact first, either the publishers or the Information Technology support group within your institution. As the instructor wrestles with this concern, time is running and students are getting anxious and frustrated.

\section{Student Awareness}

On a university-wide basis, students need to be informed about the implications of registering for an online course. The university catalogue needs to be updated to include a detailed section about online course offerings. The catalogue should contain sufficient detail regarding technical requirements regarding hardware and software that the student should have before contemplating registering for an online course. The information contained in the Master Schedule of course offerings each semester does not provide sufficient advance notice particularly for new students. At this juncture, I would like to reproduce material found in our university's Master Schedule regarding addressing a student's self-evaluation regarding an online course:

"Are online courses right for you? The online learning environment many not be the right learning environment for every student. It works well for many students; especially those constrained by schedule or other responsibilities. When considering an online course ask yourself:

- $\quad$ Do I enjoy working independently?

- $\quad$ Can I communicate effectively with small groups via computer?

- $\quad$ Am I comfortable working at the computer, following instructions on my own?

- $\quad$ Do I have access to an Internet-connected computer?

- $\quad$ Will I ask questions when I need help?

- $\quad$ Do I have experience surfing the Web and using email?

- Would I be comfortable emailing phoning or faxing my professor if I have a problem or question?

If you answered yes to most of the above questions, then the online learning environment is a good match for you. If you hesitated on a few questions, you will need to work a little harder, but would probably do fine. If you answered no to most questions, then online learning is not for you."

The above extract from our university's master schedule for Spring 2004 provides some information that students can use to make a very important decision that may impact the rest of their studies at the university. Students need above average skills in word processing, spreadsheets before enrolling for an online course.

Let me now give some anecdotal incidences that highlight the challenges of online teaching:

- $\quad$ Four weeks after classes began in the fall 2003; I received an email from a student who was enrolled in my course asking me when the online class is supposed to start. I told the student that the class began at the beginning of the semester like all the other classes. She retorted, "Why didn't you give me a call or send me an email to let me know the class had began? I was waiting to receive some communication from you about the class." This incidence clearly indicates that some students have no idea how an online class is conducted. 
- $\quad$ A week after the six week 2003 summer session had began, a student sent me an email saying that she does not know how to login.

- The course syllabus is posted under the syllabus button in Black Board. Homework assignments from the course textbook are posted in the syllabus but students are confused whether the homework is found in the textbook or is posted on Black Board.

- $\quad$ Students have difficulties locating the course after logging into Black Board.

- In spite of warnings to the contrary, students submit written assignments using software that is not compatible with the university's operating system.

\section{Course Management}

Managing an online course is a major challenge because instructors are confronted by issues that they are not trained to handle. The literature on online courses does not provide sufficient guidance on management of online courses regarding the following matters:

- $\quad$ Assignments submitted late for what student's claim to be technical reasons, examples include, Internet failure, power failure, phone lines disconnected, computer failure, software failure, etc.

- $\quad$ How to evaluate the integrity of student's work

- $\quad$ How to measure the level of interaction between the instructor and the students

- $\quad$ Alternative means of communicating with students when the system is down

- $\quad$ Alternative means of course delivery when the communications system is down

- Lost assignments

- How to evaluate group cohesion

- $\quad$ Alternative ways of evaluating student comprehension of content

\section{Course Evaluation}

This is the mother of all challenges of online teaching. The essence of an online course is to provide students opportunity to take a course when a face-to-face live physical presence is problematic. In my Managerial Accounting course, I have utilized the following methods of evaluation:

- $\quad$ Online quizzes. Each chapter has an online quiz, which must be done and submitted. A quiz can be submitted only once. There is no time limit imposed on the actual attempt on the quiz. This is a facility that is available on Black board but I have doubted its utility. The Black Board software automatically grades the quiz.

- $\quad$ Homework. The assigned weekly homework that must be submitted by the established deadline date and time. As soon as the deadline date and time are reached, I post the solution to the homework assignment. I believe this kind of immediate feedback in very important for the students. The students are provided an opportunity for immediate review of the assignment when the issues raised in the assignment are still fresh.

- Discussion Board Assignment. A series of discussion board assignments are posted for each chapter. These discussion board assignments focus on the most critical concepts in the chapter. The students are given about a week to respond to these assignments. These assignments are used to evaluate how well the students have grasped the basic concepts covered in the chapter.

- Examinations. In order to maintain an appropriate level of momentum in the course, two midterm examinations and a final examination are given. The midterm examinations are scheduled at the end of the fourth and the eighth weeks of the semester. In order to be true to the spirit of online learning, the midterm examinations are online. The examinations are posted on Black Board and the students are given a twenty four-hour window to do and submit the examination. For convenience the examination is normally posted on Friday evening and it is due on Saturday evening in order to give the students the opportunity to devote the necessary amount of time to do the examination. 


\section{Hardware, Software And Telecommunication Interfaces}

Students must have access to hardware and software that is compatible with the institution's hardware and software configurations. In regard to online courses, the master schedule for spring semester 2000 at William Paterson University has the following entry:

"Technical Requirements: The student must have access at home or on campus to a Pentium class personal computer running Windows 98 or above (or the Power Macintosh equivalent) with 32MB of RAM (64 MB recommended), 56K modem for accessing the Internet, Netscape or Internet Explorer version 4.0 or later. Students can use their own Internet Service Provider (ISP) or William Paterson University for Internet access. You should understand how to use a computer using 98-like interface (with keyboard and mouse), navigate the world wide web and know how to use email, send attachments and work with a word processor like Microsoft Word." This information is available to student's midway through the current semester for next semester's course registration. The information posted in this master schedule obviously assumes that the students are technically literate and do understand such abbreviations as MB's, RAM's and K's. How many students other than (hopefully) juniors or seniors in computer science would understand a reference such as "you should understand how to operate a computer using a Windows 98-like interface with keyboard and mouse"?

"As a difficulty of course I view the lack of personal contact and interaction between the student and the professor. On the other hand so much time is won from avoiding traffic and the general commute that it is worth it. I have taken on-line courses in the past and have no grounds for complains. With this current course I found the homework assignments to be rather lengthy. Generally speaking I see much more positive aspects associated with an on-line courses than negative. As long as one is capable of forcing himself to study on his own then there is no grounds for trouble.

\section{What Have You Found Difficult About An Online Course?}

The feedback from students on what they found difficult in the course varied widely. Some Students found the material difficult and others found the course administration cumbersome and an obstacle to learning. Here are the student's comments:

- $\quad$ The thing that I found most difficult with the course was having to learn all the material by myself. Although I found this to be the most difficult thing about this course, I really enjoyed doing it because I was able to read and complete the assignments on my own time and in the comfort of my home.

- $\quad$ The most difficult thing I found was getting the answers to homework questions after I had completing assignments.

- I found lack of flexibility a major concern. I appreciate when a course provides a student with a choice of one assignment versus another or maybe an extra credit if you found another assignment difficult.

- Also, in terms of preparations for a midterm studying without a review I found to be least useful. To achieve maximum output for time input I see a review and outline of what to concentrate on for the exam to be very productive for the students and for the sake of benefiting from the class.

- I I found it really hard to focus. Since there was a lack of feedback I found it really hard to stay motivated to do my work.

- $\quad$ I found the tests to be difficult and I am apprehensive about the final since I am so used to doing everything from home.

- I I found it hard to try to learn everything on my own. Since this was my first online course, it took me awhile to get used to it.

- The need to constantly check the computer for assignments was hard. It really made me have more discipline to try to learn the information on my own. However I have gotten used to this type of course and like that I don't have to drive there.

- What I have found difficult about the course was the workload and the difficulty in the work in general.

- $\quad$ I found that the assignments were lengthy and discussion questions often confused me. 
- I do understand that there will be a lot of work to do in an online class because we are not meeting for a lecture once or twice a week, but I felt that I was putting considerably more time and effort into this course on its assignments then I had to for my other classes. Because I found the assignments to be very challenging, it took me hours a week to complete them.

- $\quad$ The only thing that I could say was difficult was keeping up with all the assignments and their due dates.

- $\quad$ There was also a lot of pressure with the Discussion Board questions. The spelling and grammar had to be perfect, and answers had to be precise.

- At first I found it difficult to remember where to go to find all the assignments. It was confusing that in order to find homework assignments you had to go to the syllabus, then whether or not to use the digital drop box or email.

- It was difficult for me to get used to how to find all the material for the course, (probably because I didn't have the book for awhile).

- I think the most difficult thing with this course will be taking the final. Since everything as been done from home with the help from the text I think it's going to be very difficult to take the final with no help at all and too much information to know.

- $\quad$ The only thing that I really found difficult about this online course was allocating enough time to complete the assignments. It wasn't really that the assignments were all that long, but we had so many different things due on different days it was hard to keep them straight. At first I thought it would be easy to remember what was due on what days, but along with remembering things for other classes it became hard real quick. What I ended up doing was to actually put every assignment, online quiz, and discussion board question on my calendar so I wouldn't miss any. Other than this it wasn't overly difficult.

- Lack of personal contact and interaction between the student and the professor. I have taken on-line courses in the past and have no grounds for complains.

- The most difficult part of an online course I believe is the lack of extra problems and/or situations that a professor can put forth in a class setting.

- $\quad$ The only thing in my efforts that was least useful was doing the homework assignments. Some of the chapters were difficult, therefore making the homework difficult. This made my understanding and efforts more seem less useful.

- What may have been a little difficult to get used to is the fact, that one is not physically present in a classroom? One has to be more responsible about handing the work on time.

- I also found contact with the professor a little rough, since there is no in class meetings with an online course.

- $\quad$ I also felt that using student email in order to communicate with the professor was absolutely not useful for me to understand questions that I had, because many of my emails apparently did not go through.

\section{What Have You Found Least Useful In Your Efforts To Understand The Course Material?}

Much to my surprise the students found the materials posted in the discussion board to be least useful. This is certainly a matter that needs attention and analysis. The purpose of the discussion board is to discuss critical concepts in a chapter as well as to promote group unity. The discussion board in my view should promote group cohesion and reduce student isolation. This is the only forum that brings the students together as a group, otherwise they learn as isolated entities. Here are the student's views:

- The discussion board is by far the least useful.

- If I could do without one aspect of the class it would be the discussion board questions.

- $\quad$ The least useful thing I found in understanding the material was the homework assignments. They were at times quite long and if I didn't understand one question the following questions were very similar so I got them wrong as well.

- $\quad$ The least useful thing in learning the course material was probably the online quizzes although I still found them to be somewhat useful. When doing the online quizzes, I would just find the part of the chapter that the question was asking from and I don't think I retained a lot of the knowledge from the online quizzes. 
- $\quad$ Online quizzes were more of a hassle for me than anything else, but others might think differently. I just completed the assignments but rarely read the other students responses unless it was specified.

- $\quad$ I thought that the email and discussion board responses to questions posed by me as well as others were very brief and almost discourteous since I have never taken an online course before and didn't know what to expect.

\section{How Well Has The Course Met Your Personal Objectives?}

The majority of students taking managerial accounting online felt that their objectives in taking the course were met, but sometimes with reservations. Here are the students' views:

- $\quad$ The discussion groups in my opinion are a highly successful tool for the on-line educational process. They allow us to write small term-paper-like compositions, view those of other students and then have all of the above reviewed by the professor. I find this to be a very productive method to get the students to do the appropriate research and formulate their opinions and contribute to a discussion.

- I I really won't know until I move to the next level and see how much I should have gotten out of this course.

- I definitely need to get better disciplined for the next online course I take and take better advantage of the professor's time. Weighing this against the classroom scenario I would probably say the classroom experience gives you a better chance to have questions answered.

- I I feel that I learned just as much in this class as I did in any of my other accounting classes. My objectives were to gain a better understanding of managerial accounting and this class certainly achieved that goal.

- $\quad$ Everything was pretty useful for me in its own way, especially the discussion board questions. If I did not understand it in the chapter I could get different views from my other classmates on a specific topic.

- $\quad$ I feel that the discussion board questions were least useful in my efforts to understand the course materials. I found that I had a hard time taking what I had learned from reading the chapters and then responding to the questions at hand. Even when I felt that my answers were complete, we were asked to revise them and keep dissecting the questions further.

- $\quad$ Being able to do all of my homework on my own time at my own pace and knowing what the assignments were weeks in advanced has allowed me to receive grades that I believe the effort put forth into my work were worthy of. Only having to meet as a class twice (the final exam and the initial meeting) was my objective- to not have to go to school and attend another class.

- I am juggling 18 credits this semester, and this on line class just came in handy. Not having to go to class at a certain time, being able to do work from home or wherever. It has served me justice.

- I really found the information and the assignments to be useful and challenging, yet pretty easy to understand. I actually liked this course better than financial accounting, and found it more interesting and more useful for me. I pretty much just took this course because it was required, but I can honestly say that it was very interesting.

- I thought it would be a breeze taking this course online. The reading and understanding of this course were understood, but my objectives to grasp the material like I have other classes have not been met yet.

- $\quad$ This course has provided me with much flexibility. It has helped me to learn how to manage my time as far as submitting my work on time. It has helped me incorporate many things into my schedule without feeling stressed. I know when the work has to be handed in and I can pace myself.

- $\quad$ Once I got myself on track with the material, I really enjoyed the convenience for not having to commute an hour for a course. I learned that in order to take an online course you have to have a lot of selfdiscipline and motivation because you are basically on your own with all the material.

\section{Would You Advise Someone To Take An Online Course, If So Why Or Why Not?}

The majority of students taking managerial accounting online would recommend other students to take not only managerial accounting online course but other online courses too. This is how students expressed the benefits of online courses: 
- I believe this to be a wonderful way for students to manage schoolwork in a hectic lifestyle. Students are capable of devoting time to studies according to their personal schedules, whether it is during the day or at $3 \mathrm{am}$.

- I would advise anyone to take an online course because it is a great way to learn and it's also a good experience for students to have.

- I would only recommend taking an online course to people that have the ability to learn new things through a book and online interaction with the teacher and other students. If a person needs a teachers explanation in order to learn, than I would not advise them to take an online course

- $\quad$ I would only advise someone to take this kind of course if they were an easy learner.

- I wouldn't advise someone who has no idea about the course they were taking. If someone is going to selfteach they need to have a grasp of what they are learning.

- I think that more should be offered. Not having to deal with commuting and sitting through a lecture alleviates two of the things that I hate most about school.

- I enjoy being able to see a schedule in advance, which allows me to allot time in my life to get my work done at my own pace in the comfort of my own home.

- $\quad$ The work is not so bad, and professor Mwaura really stayed in touch with the students, because there are some professors that just leave it for you to figure out, but not Mwaura.

- I think it is a great way to learn and study independently. It doesn't tie too much of your time and you can fit more classes into your schedule with an online course.

- It allows you to do the work at your own pace without feeling stressed. All of the information you need is available and accessible to you.

- It gives you the freedom to take other courses.

- I probably would advise someone to take an online course as long as they are able to be motivated enough on their own to complete everything.

- We have the ability to discuss matters via the discussion board.

- We have access to course materials such as chapter notes, and we can practice our work by doing problems and quizzes.

- I would not advice someone to take an online course unless they are more confident then I was.

- I believe that you must put more time into an online course than you would in a regular class. If your position enables you to make it to class, then I would suggest making it to class. An online course is time consuming and is not worth the added stress.

\title{
Student Motivation
}

My personal opinion is that online courses are best suited for highly motivated and well-disciplined students. Probably self-starter and entrepreneurial types would make the best online students. Literature on entrepreneurs is replete with characteristics that best depict an entrepreneurial profile (McClelland, 1961, McClelland, Atkinson, Clark, 1953). These characteristics are:

\author{
- $\quad$ Need for achievement \\ - Internal locus of control and self-direction \\ - Self-confidence \\ - Awareness of the environment \\ - $\quad$ Sense if realism \\ - $\quad$ Emotional stability \\ - $\quad$ Moderate propensity for risk \\ - Opportunistic
}

If a student wishing to take an online course does not possess most of the characteristics listed above, an online course would not be appropriate. 


\section{Instructor/Student Interaction}

It is extremely important that the instructor maintains a high level of contact with students in order to maintain student morale and interest in the course. In order to meet this objective, I have used the "Discussion Board" extensively. Topical questions relating to the material being covered in text are raised for discussion in the "Discussion Board" and the students are asked to respond within a given period of time. I normally give them about a week to respond. The student has access to the contributions by other students but each must make their own contribution. I read each contribution and make comments. If a student's contribution is inadequate, I ask the student to re -write and resubmit their piece otherwise no grade will be given. A contribution may be inadequate for several reasons:

- $\quad$ The student does not demonstrate comprehension of the material

- $\quad$ The student does not present a consistent argument

- $\quad$ The contribution has grammatical and spelling mistakes

- $\quad$ The contribution does not cover all the issues raised in the discussion question

- $\quad$ The contribution is a rehash of an earlier contribution by another student.

Several times during the semester, I ask students to comment on how the course is going and to raise any issues or concerns. I have found this to be very helpful. Initially, I would post an item in the announcements button and ask the student if they have any questions. This approach was not very productive much the same way it is in a live classroom. In order to overcome this classic inertia, I ask the students to comment on specific aspects of the course such as:

- How comfortable are you with the assigned homework?

- Is the time allowed for you to submit your homework adequate?

- What problems do you have with the textbook?

- Do you understand the examples given in the textbook?

\section{Conclusion}

The challenges of online teaching are numerous and there are not enough guidelines on how to overcome them. The most critical of these challenges is the determination of the effectiveness of the learning process. There is no one teaching method, or learning style that is suitable for all teaching and learning situations. The documented approaches to effective online teaching and learning provide benchmarks for use by both teachers and learners but do not provide solutions to the many unresolved and critical concerns of distance education in general, namely the integrity of the entire process.

Access to technology and cost of resources necessary for online teaching and learning raises the perennial issue of equity. Are resources equally accessible for both teachers and learners? Are there populations that do not have access to online courses? These and others questions that are fundamental to the teaching and learning must be addressed sooner than later for online teaching and learning to impact the dissemination and assimilation of knowledge.

\section{References}

1. Fahy, Patrick, (2000). "Achieving quality with online teaching technologies." Proceedings of the Technological Education and National Development Conference, Crossroads of the New Millennium ( $2^{\text {nd }}$, April 8-10, 2000, Abu Dhabi, United Arab Emirates).

2. Gunn, Cathy (2001). "The effective online teaching - How far do the frameworks go?" In: Meeting at the Crossroads. Proceedings of the Annual Conference of the Australasian Society for Computers in Learning in Tertiary Education (ASCILITE 2001) (18th, Melbourne, Australia, December 9-12, 2001.

3. Hopper, Keith B. (2001). "Is the Internet a Classroom?" Tech Trends (Sept-Oct. 2001). 45 (5) pp. 35-43. 
4. Jones, Karyn Dayle, Karper, Chris (2000). "How to develop an online course in counseling techniques". Journal of Technology in Counseling (June), 1(2).

5. Krupa, Beata (2001). "Lessons in Change. What We Are Really Changing by Moving Education into Online Environment". Paper presented at the Popular Culture Association/American Culture Association Conference (Philadelphia, PA, April 11-14, 2001). This presentation uses notes from the 5 years of active online teaching at Jones International University as a base to examine what is changing in teaching, faculty roles, student responsibilities and collegiate culture since starting to deliver education through a network of computers.

6. Mahesh, Veena \& McIsaac, Marina Stock. (1999). "Distance Education: Learner - Teacher Interaction and time spent by teaching." Proceedings of Selected Research and Development Papers Presented at the National Convention of the Association for Educational Communications and Technology [AECT] (21st, Houston, TX, February 10-14, 1999)

7. Oliver, Martin. (2000). "Evaluating online teaching and learning. Information Services and Use", 20(2-3), p. 83-94.

8. Oliver, Ron. (1999). "Exploring strategies for online teaching and learning." Distance Education 20(2), p240-254.

9. Stephenson, John (ed.) (2001). “Teaching \& Learning Online: Pedagogies for New Technologies". Kogan Page Limited.

10. Velayo, Richard (2001). “Asynchronous Approaches to Teaching Psychology Course Online.” Paper presented at the Annual Conference of the American Psychological Association (109 ${ }^{\text {th }}$, San Francisco, CA, August 24-28, 2001).

11. White, Ken W., Weight, Bob H. (Eds.). (2000). The Online Teaching Guide: A Handbook of Attitudes, Strategies, and Techniques for the Virtual Classroom.

Notes 
Notes 